\title{
Fault Distance Measurement of Series Compensated Lines using
} ANN

\author{
A Santosh Kumar ${ }^{1}$,V. Surendranath Chowdary ${ }^{2}$, G. Kalidas Babu ${ }^{3}$ \\ ${ }^{I}$ (M.Tech Scholar, Department of Electrical Engineering, Sreenidhi Institute of Science \& Technology, \\ Hyderabad, India) \\ ${ }_{2}^{2}$ (Assistant Professor, Department of Electrical Engineering, Sreenidhi Institute of Science \& Technology, \\ Hyderabad, India) \\ ${ }^{3}$ (Assistant Professor, Department of Electrical Engineering, Nalla Narasimha Reddy Education Society's \\ Group of Institutions, Hyderabad, India)
}

\begin{abstract}
This paper presents the effects on the distance protection scheme used by the transmission lines protection system when they are compensated in series by Thyristor Controlled Series Capacitor (TCSC). The usage of TCSC introduces problems to distance protection schemes as there is a change in the measurement of apparent impedance observed by the respective relay. The change seen by the relay measurement has to be corrected for accurate operation of the particular relay, for which we take the help of Artificial Neural Networks which is extensively tested for various test conditions in MATLAB Simulation environment. The relay operation accuracy used for distance protection is improved by using the Artificial Neural Networks training methods and it also shows the distance at which the faults has occurred.
\end{abstract}

Keywords: Artificial Neural Networks, Distance protection scheme, FACTS devices, Thyristor Controlled Series Capacitor.

\section{INTRODUCTION}

The modern day power system has been forced for deregulation due to which power industry is facing limitations from the energy, environmental and regulatory issues, the main issue of an individual power engineers is to improve the power transfer capability of the given transmission facility, so that the transmission facility is used to the maximum at high efficiency. This problem can be addressed by using series compensation .Series compensation when introduced in power systems results in change of power flow in the particular network segment

Series compensation technique is a conventional and established method of increasing transmission line capacity for many years by adjusting the power transfer between two stations by adjusting the net series impedance of the line, thus increasing power transmission .Even though this method is well established method but, due to the limitation of its slow switching time it is replaced by FACTS devices which are fast acting devices due to which rapid and continues control of line compensation is possible Thyristor Controlled Series Capacitor is one of the FACTS device used for series compensation Usage of TCSC creates problems for conventional distance protection scheme. Distance protection scheme measures the apparent impedance of that particular network for which it provides protection. The apparent impedance seen by the relay is influenced by the uncertain variation of series compensation voltage.

Power Engineers normally prefer distance protection as the primary protection system. Due to the introduction of series compensation in power transmission lines they require extra care has the impedance seen by the relay changes. Modern power system protection has become intelligent has it uses micro processor based techniques for its operation. Micro processor based relays uses different types of techniques that have been widely like Expert System Techniques, Artificial Neural Networks and Fuzzy Logic Systems. Among these available techniques, Artificial Neural Networks (ANN) has been used extensively in this paper because the ANN based methods do not require a knowledge base for the location of faults unlike the other artificial intelligence based methods.

Artificial Neural Networks here uses back propagation algorithm for the improvement of the operation accuracy of distance protection when the transmission line is compensated using TCSC. ANN based back propagation algorithm is extensively tested using MATLAB Simulation for different test conditions before applying it to the commercial relay.

This paper is organized as follows: In the first section the introduction to Protection of Series Compensated Transmission Lines using ANN is discussed, in the second section simulation methods used and results are presented and in the third section conclusions based on the results obtained are presented 


\section{SIMULATION And RESULTS}

The test system used in this paper is a $500 \mathrm{KV}, 60 \mathrm{~Hz}$ power system which has two sources corresponding to two areas joined by a $400 \mathrm{~km}$ transmission line. The system parameters used for simulation are given in table (1) in Appendix. In this system the TCSC is placed in the middle of the transmission line as per the single line diagram shown in Fig. 1

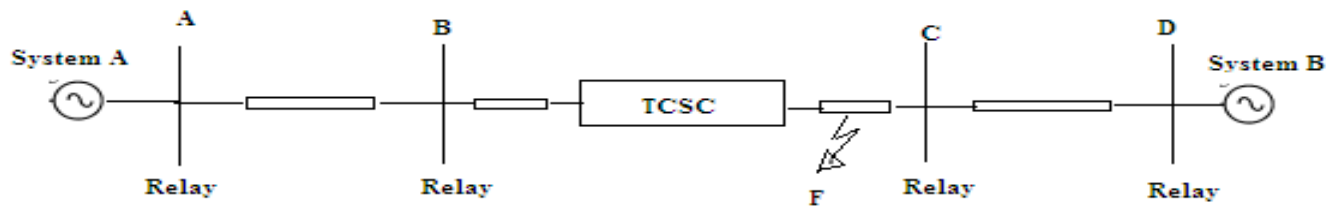

Figure: 1 Single-line diagram of the test system

The model shown in the single line diagram is modelled for computer simulation in MATLAB/Simulink environment the same is shown in Fig.2. After the simulation waveforms for different operating conditions are taken. Fig. 3 and Fig. 4 shows a three phase voltage and current waveforms without TCSC in the system. Fig.5 and Fig.6 shows the voltages and current waveforms with TCSC present in the system. Fig. 6 also shows that whenever a fault occurs on the system the fault current increases abruptly and comes to normal condition after fault is cleared. After the simulation waveforms for different operating conditions are taken from which by using the fast fourier analysis tool box present in the MATLAB tool box the voltages and currents at the relay are calculated. Based up on the values of voltages and currents at different test conditions and different fault conditions impedance of that particular line section is calculated and the results are presented in table (1).

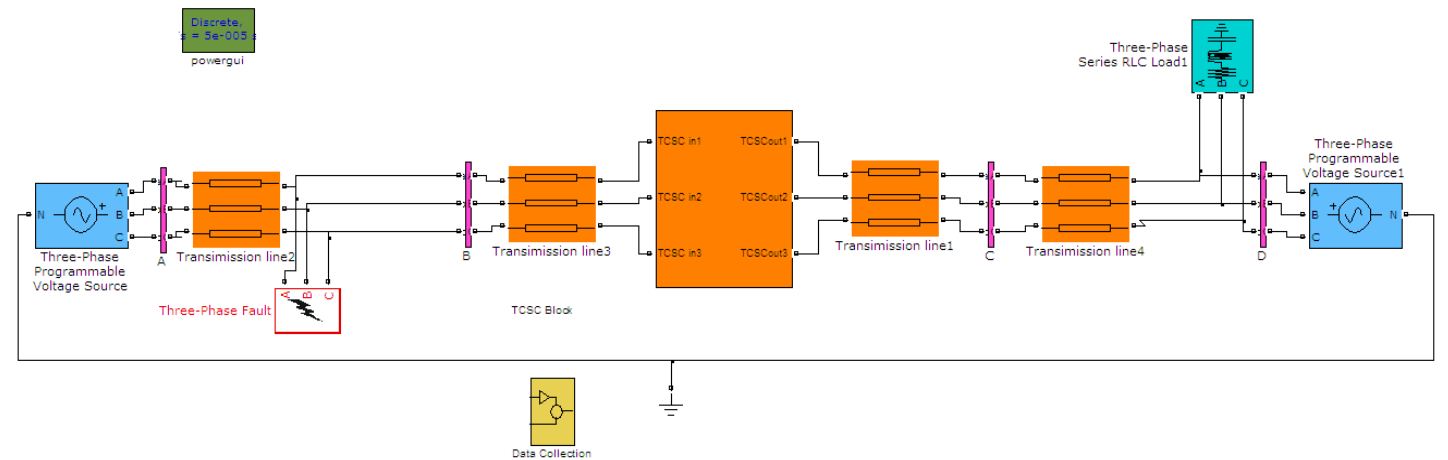

Figure: 2 Simulation model with TCSC in the middle

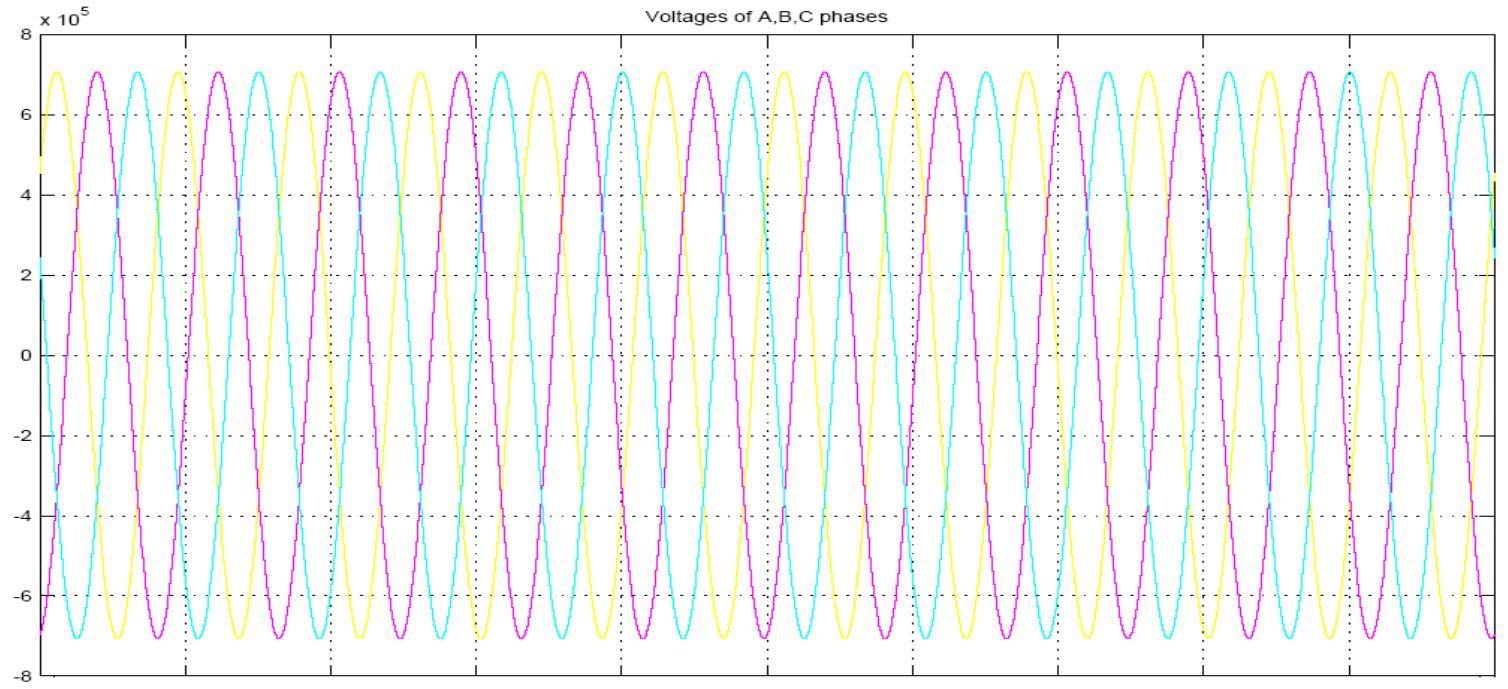

Figure: 3 Voltage waveforms without TCSC 


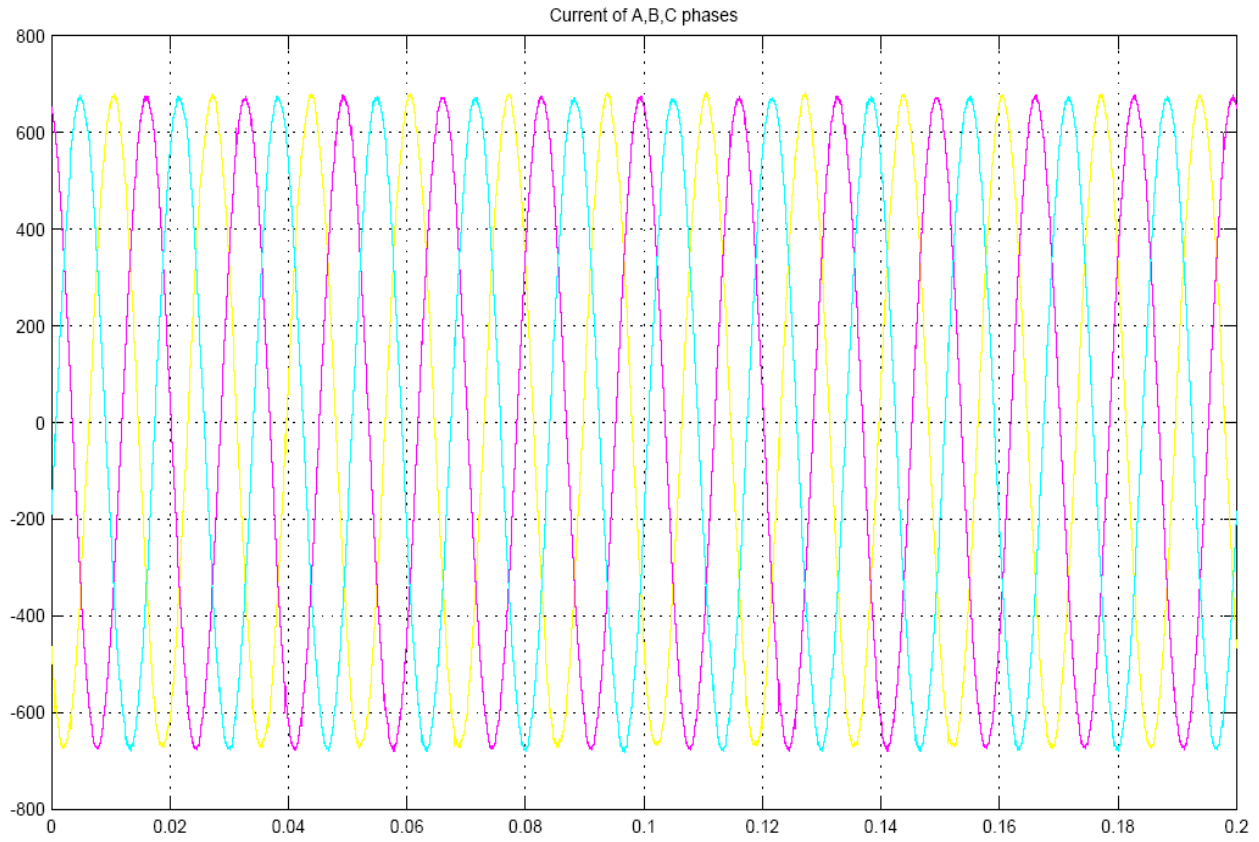

Figure: 4 Current waveforms without TCSC

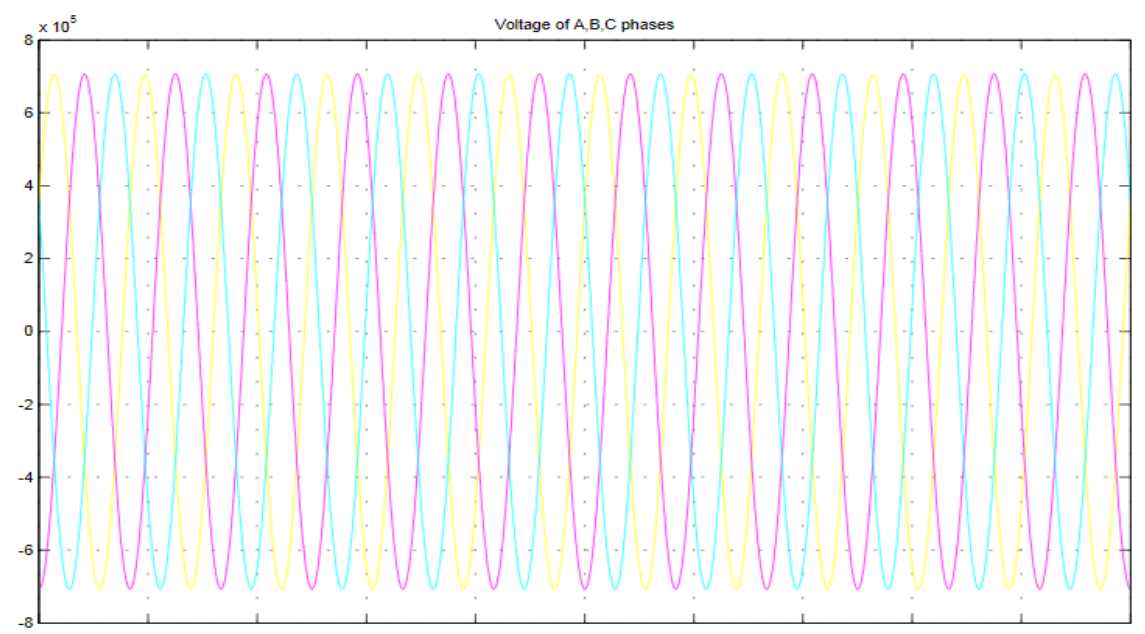

Figure: 5 Voltage waveforms with TCSC in capacitive mode of operation

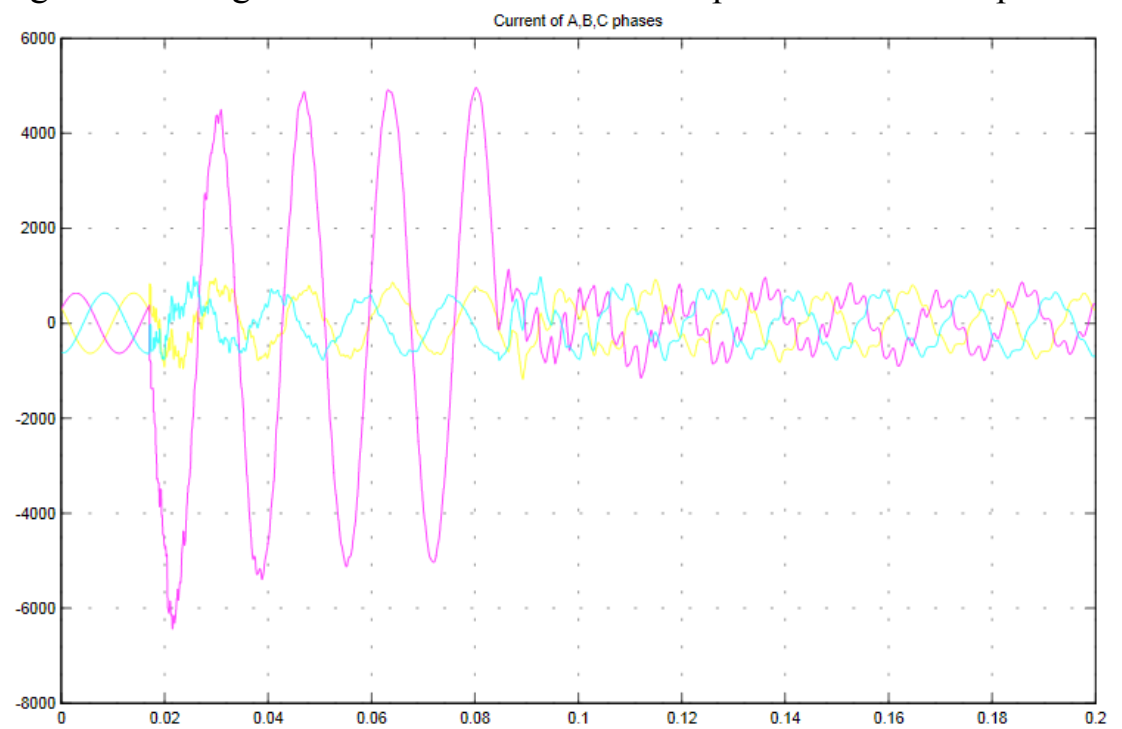

Figure: 6 Current waveforms with TCSC in capacitive mode of operation 
Table: 1 Impedance values with TCSC in the middle of the line

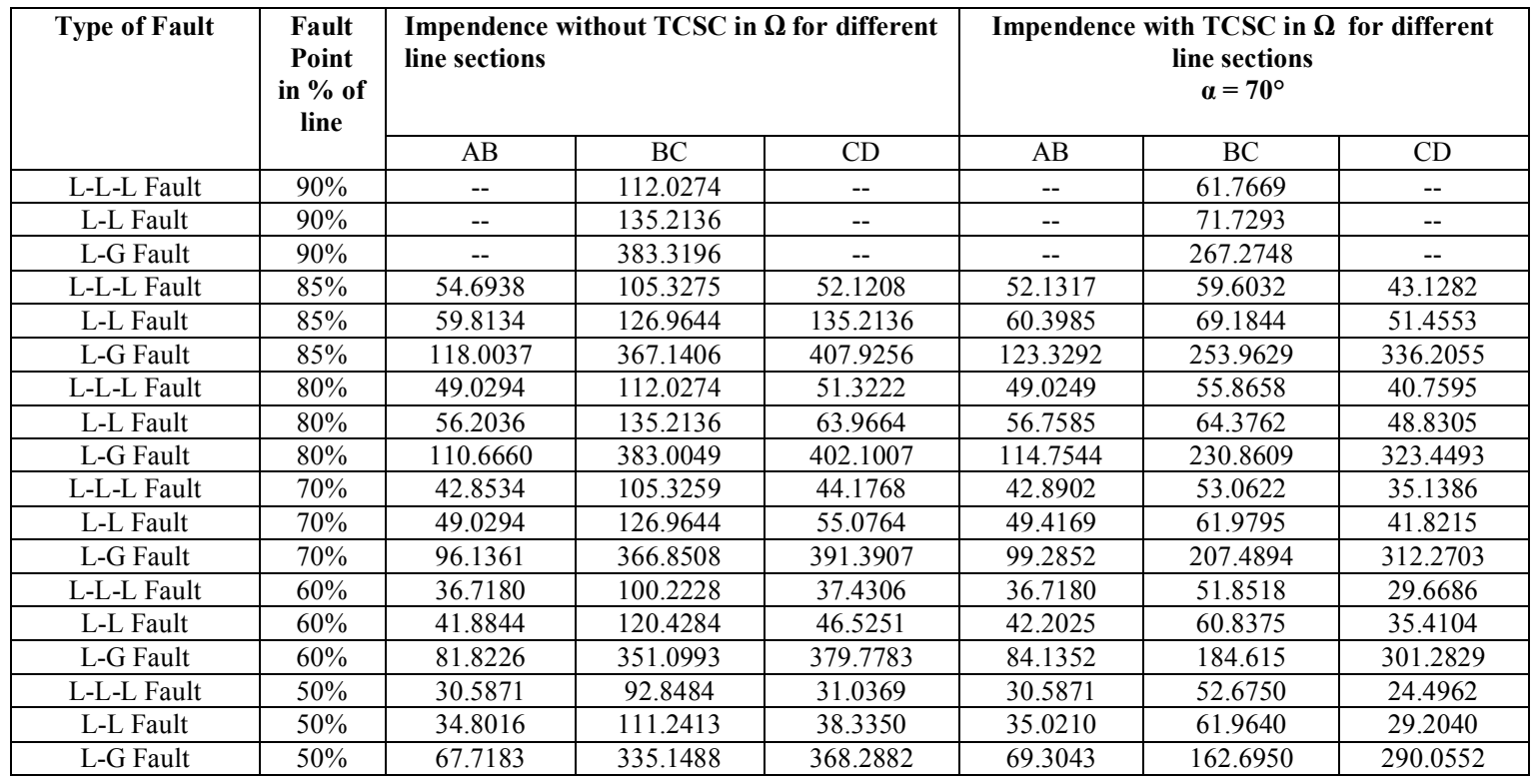

Table: 2 Protection behavior of the relay in the particular line section

\begin{tabular}{|c|c|c|c|c|}
\hline \multirow{2}{*}{ Type of Fault } & $\begin{array}{c}\text { Fault Point in \% of } \\
\text { line }\end{array}$ & \multicolumn{2}{|c|}{ Trip/No Trip of the relay based on impendence calculated } \\
\cline { 2 - 4 } & $90 \%$ & $\mathrm{AB}$ & BC & CD \\
\hline L-L-L Fault & $90 \%$ & -- & Trip & -- \\
\hline L-L Fault & $90 \%$ & -- & Trip & -- \\
\hline L-G Fault & $85 \%$ & No Trip & Trip & Trip \\
\hline L-L-L Fault & $85 \%$ & No Trip & Trip & Trip \\
\hline L-L Fault & $85 \%$ & No Trip & Trip & Trip \\
\hline L-G Fault & $80 \%$ & Trip & Trip & Trip \\
\hline L-L-L Fault & $80 \%$ & Trip & Trip & Trip \\
\hline L-L Fault & $80 \%$ & Trip & Trip & Trip \\
\hline L-G Fault & $70 \%$ & Trip & Trip & Trip \\
\hline L-L-L Fault & $70 \%$ & Trip & Trip & Trip \\
\hline L-L Fault & $70 \%$ & Trip & Trip & Trip \\
\hline L-G Fault & $60 \%$ & Trip & Trip & Trip \\
\hline L-L-L Fault & $60 \%$ & Trip & Trip & Trip \\
\hline L-L Fault & $60 \%$ & Trip & Trip & Trip \\
\hline L-G Fault & $50 \%$ & Trip & Trip & Trip \\
\hline L-L-L Fault & $50 \%$ & Trip & Trip & Trip \\
\hline L-L Fault & $50 \%$ & Trip & Trip & \\
\hline L-G Fault & & & & \\
\hline
\end{tabular}

Table: 3 Distance measurement made by the relay for different types of faults

\begin{tabular}{|c|c|c|c|}
\hline Type of Fault & Fault Point of a given line & $\begin{array}{c}\text { Distance shown by the relay for a } \\
\text { transmission line in Per units }\end{array}$ & $\begin{array}{c}\text { Distance shown by the relay for a } \\
\text { compensated transmission line in } \\
\text { Per units }\end{array}$ \\
\hline L-L-L Fault & $90 \%$ & 0.90 & 0.49 \\
\hline L-L Fault & $90 \%$ & 0.90 & 0.477 \\
\hline L-G Fault & $90 \%$ & 0.90 & 0.627 \\
\hline L-L-L Fault & $85 \%$ & 0.85 & 0.48 \\
\hline L-L Fault & $85 \%$ & 0.85 & 0.468 \\
\hline L-G Fault & $85 \%$ & 0.85 & 0.587 \\
\hline L-L-L Fault & $80 \%$ & 0.80 & 0.398 \\
\hline L-L Fault & $80 \%$ & 0.80 & 0.3808 \\
\hline L-G Fault & $80 \%$ & 0.80 & 0.4822 \\
\hline L-L-L Fault & $70 \%$ & 0.70 & 0.3526 \\
\hline L-L Fault & $70 \%$ & 0.70 & 0.3417 \\
\hline L-G Fault & $70 \%$ & 0.70 & 0.3959 \\
\hline L-L-L Fault & $60 \%$ & 0.60 & 0.3104 \\
\hline L-L Fault & $60 \%$ & 0.60 & 0.3031 \\
\hline L-G Fault & $60 \%$ & 0.60 & 0.3154 \\
\hline L-L-L Fault & $50 \%$ & 0.50 & 0.2836 \\
\hline L-L Fault & $50 \%$ & 0.50 & 0.2785 \\
\hline L-G Fault & $50 \%$ & 0.50 & 0.2427 \\
\hline
\end{tabular}




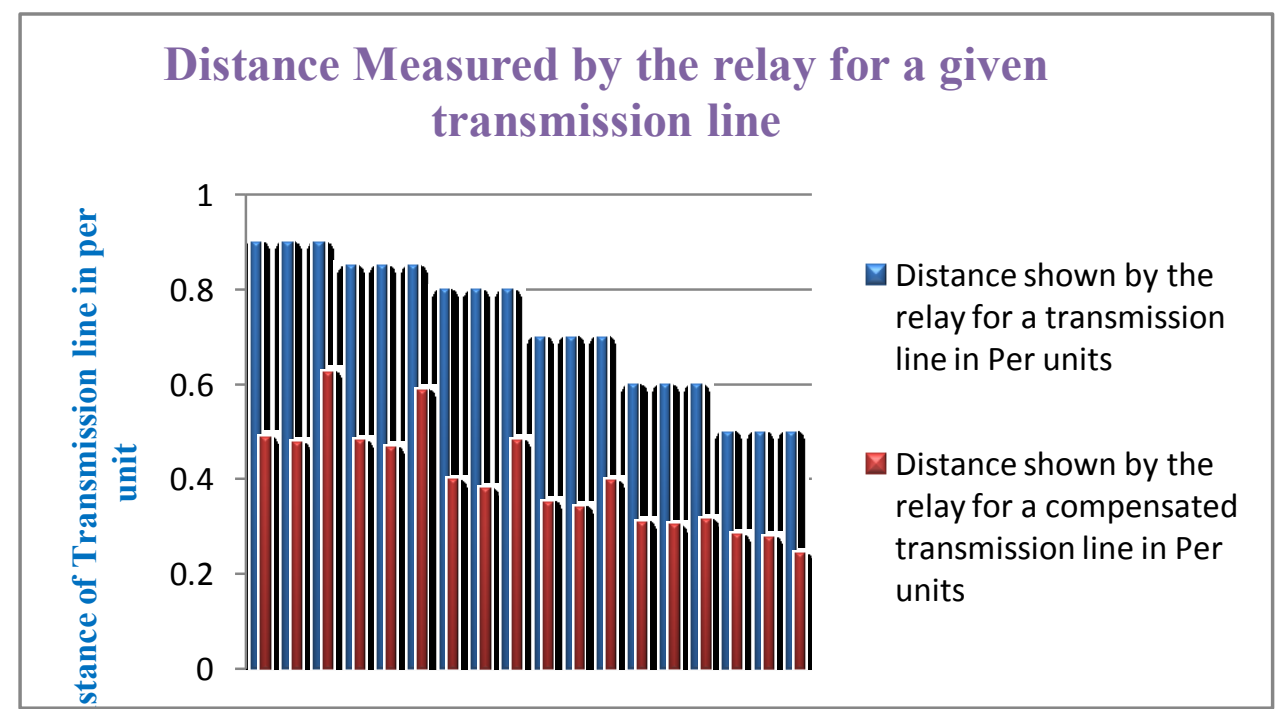

Figure: 7 Bar Graph showing Comparison of Distance measured by the relay for uncompensated and compensated transmission line

Based on the results of TABLE (1) the relay present for protection of that particular zone sends a wrong trip signals which is shown in TABLE (2). From the results obtained from TABLE (1) and TABLE (3), we can clearly say that the usage of TCSC as resulted in a drastically change of impedance measurement due to which the relay shows wrong distance measurement this is the main problem faced by the protection circuit due to which a wrong signal is sent to the circuit breaker which has to be corrected, the change in impedance measurement and the distance measurement shown by the respective relay used for protection is corrected with the help of Artificial Neural Network. TABLE (3) shows the distance measurement in per unit values from this we can clearly understand that distance shown by the relay is erroneous with respect to the expected value which is also shown in the form of bar graph for better picture as shown in Fig 7.This error in distance measurement can be corrected by using the same ANN.

The training cases used for the training of the ANN are generated using MATLAB/Simulink test system shown in Fig. 1 for various kinds of faults (LLL-Fault, LL-Fault and LG-Fault) fault location (90\%, $85 \%, 80 \%, 70 \%, 60 \%$ and $50 \%$ length of line) and with different firing angles of TCSC $\left(60^{\circ}, 63^{\circ}, 65^{\circ}, 68^{\circ}\right.$ and $70^{\circ}$ ), with all the above different training cases different training vectors were collected at a sampling rate of 16 samples/cycle. The inputs given for the training of ANN are voltage, current of the relay location and firing angle at which TCSC is operating. The output expected from the ANN system is trip or a no trip signal to the

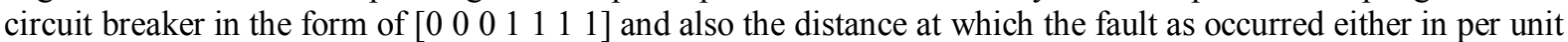
value, or in kilometres or in miles as per the training. ANN uses back- propagation algorithm for its training purpose and the number of neurons in the hidden layer is decided based on the trial and error method. In the present problem based on the trial and error method we come to the conclusion that with 10 neurons in the hidden layer gives better results with a Mean Square error of $2.9577 \times 10^{-14}$.The results for expected output and the output obtained after training are compared as shown in TABLE (4). The results obtained in the TABLE (4) are plotted in the form of bar graph for better understanding as shown in Fig. 8. TABLE (5) compares the distance shown by the relay before and after the training if we just have a look at the results we understand that the problem as shown in the TABLE (3) has been corrected. The results obtained in TABLE (5) are again plotted in the form of bar graph as shown in the Fig. 9 to get a quick understanding.

Table: 4 Comparison of Output of Conventional Relay Output with ANN output

\begin{tabular}{|c|c|c|}
\hline $\begin{array}{c}\text { Expected } \\
\text { Output of ANN Network }\end{array}$ & $\begin{array}{c}\text { Conventional Relay } \\
\text { Output }\end{array}$ & Output of ANN Based Relay \\
\hline 0 & 1 & 0.0566915 \\
\hline 0 & 1 & 0.0467832 \\
\hline 0 & 1 & 0.0477842 \\
\hline 1 & 1 & 0.99997 \\
\hline 1 & 1 & 0.95266 \\
\hline 1 & 1 & 0.99999 \\
\hline 1 & 1 & 0.99996 \\
\hline
\end{tabular}




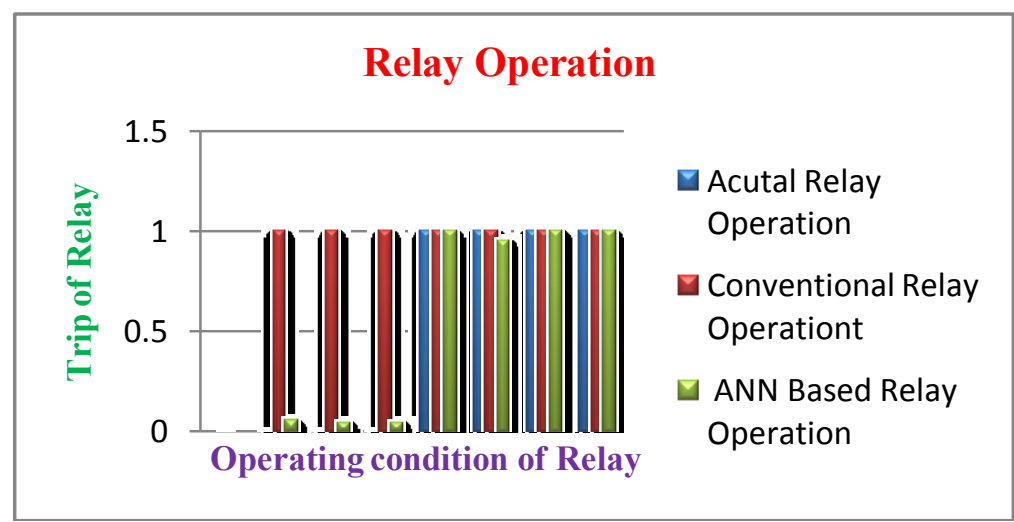

Figure: 8 Bar Graph showing Comparison of Output of Conventional Relay Output with ANN output

Table: 5 Comparison of Output of Conventional Relay Output with ANN output for Distance Measurement in

\begin{tabular}{|c|c|c|}
\hline $\begin{array}{c}\text { Expected Output of ANN } \\
\text { Network for Distance } \\
\text { Measurement in Per Units }\end{array}$ & $\begin{array}{c}\text { per units } \\
\text { Conventional Relay Output for Distance } \\
\text { Measurement in Per Units }\end{array}$ & $\begin{array}{c}\text { Output of ANN Based Relay for } \\
\text { Distance Measurement in Per Units }\end{array}$ \\
\hline 0.85 & 0.58 & 0.85 \\
\hline 0.80 & 0.48 & 0.80 \\
\hline 0.70 & 0.39 & 0.70 \\
\hline 0.60 & 0.31 & 0.60 \\
\hline 0.50 & 0.24 & 0.50 \\
\hline
\end{tabular}

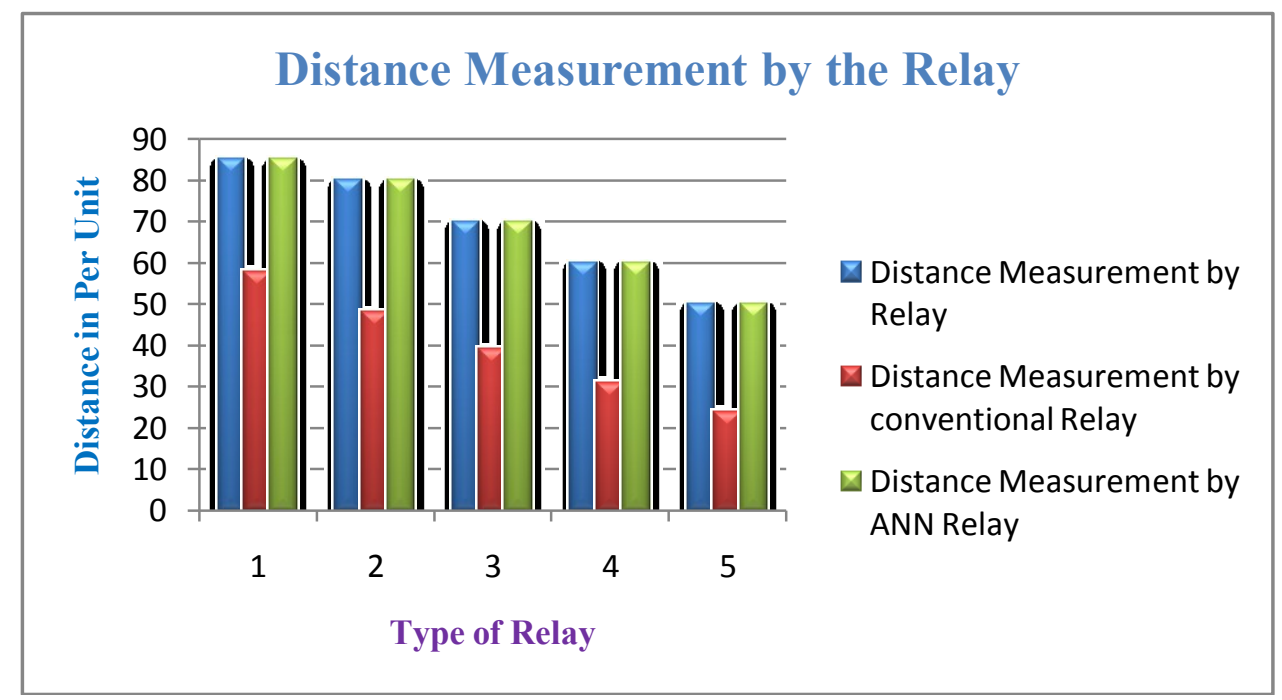

Figure: 9 Bar Graph showing Comparison of Distance Measurement of Conventional Relay Output with ANN output

\section{Conclusions}

The usage of TCSC in transmission lines has advantages like improvement in stability; enhanced active power transfer capability, but it also results in problems for conventional distance protection scheme used by respective transmission lines as there is an error in the apparent impedance measured by the relay which in turn shows the wrong distance measurement. The results obtained from simulation for different types of faults and different operating points (with firing angles $\alpha=60^{\circ}$ to $70^{\circ}$ ) of TCSC indicate that presences of TCSC when in operation will change the impedance measured by the relays used by the protection system, which causes mal operations (like over reach) of protective relay and also shows wrong distance measurement. This mal operation is avoided by ANN training by Back Propagation Algorithm. ANN based relay gives promising results (for tripping condition $(0,1)$ and also the correct distance where the fault has occurred) compared to conventional relay with the presences of TCSC. 
Table 1 System parameters used for simulation

\begin{tabular}{|c|c|}
\hline LINE & \multicolumn{2}{|c|}{} \\
\hline Length & $400[\mathrm{~km}]$ \\
\hline Voltage & $500[\mathrm{kV}]$ \\
\hline Compensation & $75 \%$ \\
\hline positive sequence impedance & $0.01273+\mathrm{j} 0.352[\mathrm{ohm} / \mathrm{km}]$ \\
\hline zero sequence impedance & $0.3864+\mathrm{j} 1.5556[\mathrm{ohm} / \mathrm{km}]$ \\
\hline ROV & $330[\mathrm{kV}]$ \\
\hline Reference current & $1000[\mathrm{~A}]$ \\
\hline Exponent & 25 \\
\hline \multicolumn{2}{|c|}{$1 \mathrm{p.u}}$. \\
\hline IV11 & $1.01 \mathrm{p} . \mathrm{u}$. \\
\hline IV2I & $10[\mathrm{deg}]$ \\
\hline
\end{tabular}

\section{REFERENCES}

[1] Alireza Solat, and Ali Deihimi, "A Novel Scheme for Distance Protection of Series Compensated Transmission Lines with TCSC Using Artificial Neural Netwoks", $20^{\text {th }}$ Iranian Conference on Electrical Engineering, (ICEE2012), May 15-17, 2012.

[2] Zellagui Mohamed and Chaghi Abdelaziz, "Impact of Series Compensation Insertion in Double HV Transmission Line on the Settings of Distance Protection”, International Journal of Scientific \& Engineering Research Volume 2, Issue 8, August-2011, pp.17.

[3] Mojtaba Khederzadeh and T. S.Sidhu, "Impact of TCSC on the Protection of Transmission Lines", IEEE Transactions on Power Delivery, Volume 21 January 2006, pp.80-87.

[4] A Santosh Kumar and V Surendranath Chowdary, "ANN Based Prottection for Series Compensated Lines", International Journal of Advanced Research in Electrical, Electronics and Instrumentation Engineering, Volume. 2, Issue 7, July 2013.

[5] Sarath Kapuduwage, "Fault Location on the High Voltage Series Compensated Power Transmission Networks", Thesis, December $21,2006$.

[6] S. G. Srivani and K. PandurangaVittal, "Integrated Adaptive Reach Setting of Distance Relaying Scheme in Series Compensated Lines", International Journal on Electrical Engineering and Informatics - Volume 2, no. 4, 2010, pp.291-297.

[7] Suhaas Bhargava Ayyagari, “Artificial Neural Network Based Fault Location for Transmission Lines", Thesis, June 12, 2011.

[8] Sunita Tiwari and S.P. Shukla, "COMPENSATION BY TCSC IN OPEN LOOP CONTROL SYSTEM", IJAET/Vol.III/ Issue I/January-March, 2012, pp.175-179.

[9] Upendar, C. P. Gupta, and G. K. Singh," Comprehensive Adaptive Distance Relaying Scheme for Parallel Transmission Lines" Transactions on Power Delivery, Volume 26, no. 2, April 2011, pp.1039-1059.

[10] Dragan Jovcic and G. N. Pillai "Analytical Modelling of TCSC Dynamics" IEEE Transactions on Power Delivery, Volume 20, no. 2, April 2005, pp.1097-1104.

[11] A.H. Osman, Tamer Abdelazim and O.P. Malik, "Transmission Line Distance Relaying Using On-Line Trained Neural Networks", Transactions on Power Delivery, Volume 20, no. 2, April 2005, pp.1257-1264.

[12] Clint T. Summers, "Distance Protection Aspects of Transmission Lines Equipped with Series Compensation Capacitors", Thesis September 29, 1999.

[13] B. Ram \& D.N. Vishwakarma, "Power system protection and switchgear", Tata McGraw- Hill Publishing Company Limited, New Delhi 1995.

[14] Hingorani NG, Gyugyi L. Understanding FACTS: concepts and technology of flexible AC transmission systems, New York: IEEE Press; 1999.

[15] Sivanandam, S.N. Deepa, "Introduction to Neural Networks using MATLAB 6.0”, Tata McGraw- Hill Publishing Company Limited, New Delhi 2006.

\section{BIOGRAPHY}

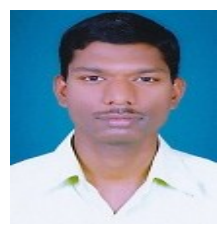

A Santosh Kumar received his B.Tech degree from Sri Indu College of Engineering and Technology in the year 2007, and he is pursuing his Masters in Electrical Power Engineering from Sreenidhi Institute of Science and Technology Hyderabad. His areas of interests include Power System Protection, Power Quality and Artificial Intelligences.

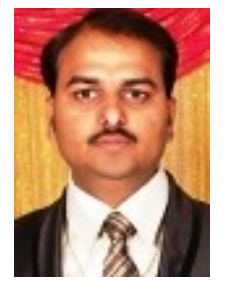

V Surendranath Chowdary received his B.Tech degree from JNTUH in year 2006 and M.Tech in Power Systems in 2008 from JNTUH. He is currently working as Assistant Professor of EEE Department in Sreenidhi Institute of Science and Technology. His areas of interests include Power System Protection, Power Harmonics, Power Quality and Artificial Intelligences 
G Kalidas Babu received his B.Tech degree from LBRCE, JNTUH in year 2002 and M.Tech in Power System Engineering in 2008 from NIT Warangal. He is currently working as Assistant Professor of EEE Department in Nalla Narasimha Reddy School of Engineering. His areas of interests are Reactive Power Control Issues, Alternative Energy Sources and Deregulation Issues. 